\title{
Comerciantes y redes desde el puerto boliviano de Cobija
}

\section{Merchants and networks from the Bolivian port of Cobija}

Viviana E. Conti ${ }^{1}$

\section{Resumen:}

El artículo se centra en el puerto boliviano de Cobija, durante su breve operación en el contexto histórico de América de Sur. Se releva su papel de enlace entre el mercado mundial y los centros urbanos y mercantiles del interior del continente, los que a su vez distribuían las mercancías en el interior del espacio surandino. Se aborda la construcción de las redes mercantiles y las prácticas comerciales del puerto de Lamar y se identifican y califican a los sectores mercantiles según los montos de las transacciones realizadas con bienes de ultramar ingresados a la aduana. La investigación usa nuevas fuentes sobre temas ya abordados.

1 Investigadora del Consejo Nacional de Investigaciones Científicas y Técnicas (CONICET) y de la Universidad Nacional de Jujuy (Argentina). Contacto: vivconti@gmail.com 
Palabras clave: comercio marítimo, redes comerciales, puerto de Cobija (Bolivia), puerto Lamar (Bolivia), América del Sur, siglo XIX

\section{Abstract}

The article focuses on the Bolivian port of Cobija, during its brief operation in the historical context of South America. Its role as a link between the world market and the urban and mercantile centers of the interior of the continent, which in turn distributed the goods in the interior of the SouthAndean space is highlighted. The construction of mercantile networks and the commercial practices of the port of Lamar are dealt with and the mercantile sectors are identified and qualified according to the amounts of the transactions carried out with overseas goods entered to the customs. The research uses new sources on topics already addressed.

Key words: maritime trade, trade networks, port of Cobija (Bolivia), port of Lamar (Bolivia), South America, $19^{\text {th }}$ century

\section{Introducción}

En las últimas décadas de la colonia, la Villa Imperial de Potosí, centro de producción argentífera y de demanda y comercialización de diversos bienes, se conectaba con España y el mercado mundial a través de dos grandes circuitos: el del Pacífico -por los puertos del Callao y Arica- y el del Atlántico por Buenos Aires, que eran los puertos más cercanos autorizados por la Corona (Reglamento y aranceles reales para el comercio libre de Espańa a Indias de 12 de octubre de 1778 , p. 9) y, a la vez, con redes mercantiles establecidas 
por las demandas del abastecimiento potosino de larga data (Roca, 2011, p. 82; Escobari de Querejazu, 2014, pp. 82-85; Milletich, 2000, p. 225; Rosenblitt, 2014).

El circuito de la sierra, que enlazaba a Potosí con Cuzco y Lima (el Callao), era el más antiguo y seguía utilizándose a fines del siglo XVIII, pese a tener tramos muy peligrosos y el cruce de caudalosos ríos (Escobari de Querejazu, 2014, pp. 82-84). El camino que iba al puerto de Arica era surcado por una red de arrieros-comerciantes, reemplazados desde el siglo XVIII por comerciantes limeños y peninsulares (Rosenblitt, 2014, 2017); tenía la ventaja de comunicarse directamente con La Paz, por tanto, fue un circuito preponderante para la introducción de efectos de Castilla al Alto Perú. El circuito Potosí-Buenos Aires gozaba de ciertas virtudes por ser el camino carretero entre Jujuy y el puerto; fue la ruta utilizada desde el siglo XVII para la provisión de mulas al Alto Perú y la compra de tocuyos demandados en la zona pampeana, a la vez que era la ruta del situado, por tanto, contaba con redes de comerciantes y tratantes que trajinaban entre Buenos Aires-Potosí-Lima. A fines del siglo XVIII, el circuito entre Buenos Aires y Potosí fue tomando relevancia en el abastecimiento minero (Milletich, 2000, pp. 232-233).

Desde los comienzos del período republicano, la apertura de distintos puertos menores, competitivos en aranceles y distancias, presentaron alternativas que variaron la dirección de los flujos y beneficiaron a pequeñas regiones en el interior del espacio surandino. Aquí nos detendremos en el puerto de Cobija y sus lazos mercantiles.

El puerto de La Magdalena de Cobija fue oficializado como puerto mayor de Bolivia por Simón Bolívar en diciembre de 
1825, al que bautizó como puerto de Lamar. Ubicado en la costa del océano Pacífico, estaba emplazado en la zona del desierto de Atacama, con difícil acceso a las ciudades del interior, lo que fue desarrollando una extensa red de arrieraje - con base en el oasis de Calama- heredera de la arriería indígena colonial que llevaba fletes de pescado a través del desierto de Atacama hasta los mercados mineros del Alto Perú a fin de cambiarlo por plata y productos de los valles (Sanhueza, 2011, pp. 316-322; Albeck, Conti y Ruiz, 2003).

El puerto recibió distintos beneficios políticos: una legislación aduanera diferencial del resto de Bolivia, un sistema de postas y privilegios y el mejoramiento de fletes y arriería, lo que facilitó la conexión oficial de la República de Bolivia con el mercado mundial. Por él se exportaban los minerales extraídos de los asientos mineros bolivianos y se importaban las mercancías provenientes del mercado mundial (Cajías, 1975). Funcionó desde 1827 hasta 1877 y en ese medio siglo desarrolló un intenso movimiento mercantil, de pasajeros y de abastecimiento de la población costera y de los oasis cercanos, lo cual cambió la fisonomía de los oasis cercanos (Palliere, s. f., pp. 183-185; Tschudi, 1860, pp. 388 y ss.; Phillipi, 1860 , pp. 52 y ss.) y la dirección de los circuitos comerciales tradicionales con el Atlántico (Conti, 2001, 2007, 2008).

244 Este artículo trata las conexiones y redes mercantiles que se fueron gestando desde el puerto de Lamar hasta el interior del espacio surandino. Se ha hecho un análisis minucioso del año 1841, tomado como ańo testigo entre la década anterior ${ }^{2}$ y la década de 1840, que asistió al crecimiento del puerto de Lamar

2 La década de 1830 está enmarcada por la Confederación Peruano-Boliviana y la guerra con la Confederación Argentina y con Chile; fue tam- 
manifestado en los volúmenes y valores de las importaciones $(\mathrm{ABNB}, \mathrm{AHP})^{3} \mathrm{y}$, consecuentemente, en la importancia que fueron adquiriendo las redes mercantiles del sector importador en los Andes del sur. Se ha estudiado a los agentes comerciales del puerto y de las principales ciudades del interior del continente, sus lazos y las prácticas mercantiles desarrolladas en torno a las importaciones arribadas a la aduana de Lamar.

Se parte de la hipótesis de que el puerto boliviano de Lamar se convirtió en un conector de distintas zonas del interior del espacio surandino con el mercado mundial; la hipótesis se sustenta en decisiones políticas del Estado boliviano (en temas fiscales y de privilegio) y en el sostén y redefinición de vastas redes mercantiles que se extendían en el interior del continente, más allá de los límites políticos de los Estados.

La primera parte de esta hipótesis se ha basado en la legislación del puerto de Lamar desde 1826 hasta 1850 y se ha hecho un análisis comparativo de la legislación vigente en los puertos de Lamar, Valparaíso y Buenos Aires (leyes de aduanas, aranceles, reglamentos, derechos portuarios), los gastos de transporte de las mercancías (fletes, derechos de tránsito) y las vinculaciones sociales como parte de las prácticas mercantiles de la época (Conti, 2014, 2017).

El análisis se centra en las redes de importación de bienes de ultramar. La base de esas vinculaciones se encuentran en el

bién escenario de las invasiones peruanas a Cobija de 1828, 1831 y 1835. Fue estudiada por Fernando Cajías (1975).

3 Archivo y Biblioteca Nacionales de Bolivia (ABNB) y Archivo Histórico de Potosí (AHP). Los periódicos El Restaurador y El Celaje dan cuenta del arribo de buques y el movimiento de pasajeros. 
sector exportador de ganado vacuno y mular, que durante más de un siglo conectaron las zonas productoras a través de comerciantes del norte rioplatense con los usuarios en el Alto y Bajo Perú, con retornos de metálico (Assadourian, 1983; Sánchez Albornoz, 1965; Mata, 1993; Conti, 2003, entre otros autores).

En este estudio, se emplearon como testimonios principales las fuentes aduaneras de Lamar, Potosí y Salta entre los años 1828 y 1850 . El recorte temporal se debe al comienzo de las importaciones de envergadura y la posterior conversión de Cobija en un mero puerto de tránsito de Valparaíso (ABNB, Anónimo, 1863, p. 8). ${ }^{4}$ Se desconoce bibliografía que haya explorado este espacio y recorte temporal con la misma óptica, salvo la mencionada.

Las fuentes aduaneras permiten conocer el movimiento de importaciones y exportaciones legales, en volúmenes y valores de aforo, derechos aplicados a ellos, cuando existieran, e identificar a los comerciantes que extrajeron las mercancías $y$, en las reventas, quiénes las revendieron y a qué comerciantes, así como su ubicación (lo que indica el circuito de las mercancías), las garantías dejadas y los intereses cobrados, cuando los hubiera. Lamentablemente, estas fuentes no existen para todos los ańos estudiados en las tres aduanas selec246 cionadas, aunque sí las suficientes para realizar un cruce en-

4 Se ha elegido esta fuente por ser un testimonio de primera mano, escrito por "un vecino de Cobija" y debido a su utilización por el Estado boliviano al planificar un nuevo camino de acceso a Cobija. La cuestión en sí misma (conversión de Lamar en un puerto totalmente subsidiario de Valparaíso) se relaciona con la emisión monetaria y excede los límites de este artículo. 
tre ellas y seleccionar "años testigos", que permiten analizar en profundidad el desarrollo y direcciones del movimiento comercial del sector importador para conocer los circuitos mercantiles y las vinculaciones de los comerciantes.

El procesamiento de las fuentes aduaneras se realizó día por día, desagregando las introducciones a las aduanas de los bienes procedentes del mercado mundial (importaciones de efectos de ultramar) y sus reventas a otros destinos. En caso de encontrarse entre ellos bienes de distintas regiones de Hispanoamérica (cacao, añil, textiles de la tierra, coca, yerba mate, azúcar, etc.), el procedimiento seguido fue desagregarlos, a fin de trabajar solo los llamados "efectos de ultramar". Los valores con los que se elaboraron las series se extrajeron de las guías y los manifiestos de introducción presentados en las aduanas al momento de retirar las mercancías. Las fuentes aduaneras fueron completadas con la información brindada por la legislación, protocolos de escribanos, periódicos, correspondencia y los viajeros.

\section{Circuitos mercantiles desde Lamar hasta el interior del espacio surandino}

A partir de la independencia de Bolivia (agosto de 1825), la conexión de las plazas mercantiles con el mercado mundial se realizó a través de los puertos de Buenos Aires (vía Salta o Jujuy) y Arica (vía Tacna y La Paz). ${ }^{5}$ En 1826, pocos meses después de la independencia del Alto Perú y la emergencia de la República de Bolivia, Joseph Barclay Pentland observó que

5 ABNB, Tribunal Nacional de Cuentas (TNC) 3363: Libro principal de guías de la Real Aduana de Potosí, 1825. 
en los ańos 1825 y 1826 el comercio de importaciones se dividía entre los puertos de Buenos Aires y Arica; ${ }^{6}$ para entonces, en el puerto peruano ya existían nueve casas comerciales británicas subsidiarias de Valparaíso, también una francesa, una alemana, dos de Buenos Aires y dos de los Estados Unidos de Norteamérica (Pentland, 1975, p. 111).

El circuito Buenos Aires-Potosí reactivó las redes mercantiles de las últimas décadas coloniales, pero en 1826 la plaza potosina estaba saturada, lo que motivó que muchos comerciantes regresaran las mercancías a las casas comerciales importadoras; ${ }^{7}$ a ello se sumaba el no reconocimiento de la República de Bolivia por parte de la efímera presidencia de Rivadavia en Argentina, lo que frenó la actividad comercial por el puerto de Buenos Aires (Pentland, 1975).

Durante casi todo el año 1827, el único puerto de importación de Bolivia fue Arica y hubo reducido movimiento comercial desde Quilca, vía Arequipa. Las importaciones entradas por Lamar arribaron a Potosí en los últimos dos meses de $1827 .{ }^{8}$

Al observar el movimiento mercantil de la ciudad de Potosí
entre 1825 y $1828^{9}$ a través de los libros de la aduana, se ad-
vierte que durante 1825 y 1826 se mantuvo la tensión entre

6 ABNB, TNC. 3358: Libro principal de guias de la Aduana Nacional de Potosi, 1826. Las fuentes aduaneras confirman lo expuesto por Joseph Pentland.

7 - ANB, TNC. 3366: Documentos de data desde el número $1^{\circ}$ hasta el 48, de la cuenta de la Aduana Nacional de Potosí del año 1826.

8 ABNB, TNC 2298: Libro auxiliar de guías de la Aduana Nacional de Potosí, 1827.

9 Período que va desde la independencia hasta la entrada en vigencia de la reglamentación, la instalación de los primeros comerciantes en el nuevo 
los dos circuitos, desde el Atlántico y desde el Pacífico, mientras que durante el año 1827 la mercancía europea ingresó solo por el puerto de Arica, con guías emitidas en Tacna. Recién en septiembre de 1827 comenzaron a entrar en la aduana de Potosí las importaciones provenientes del puerto de Lamar. ${ }^{10}$

El gráfico 1 expresa los ingresos de mercancías provenientes del mercado mundial al puerto de Lamar entre 1828 y 1838 y las oscilaciones en las importaciones.

\section{Gráfico 1. Importaciones del puerto de Lamar entre 1828 y 1838}

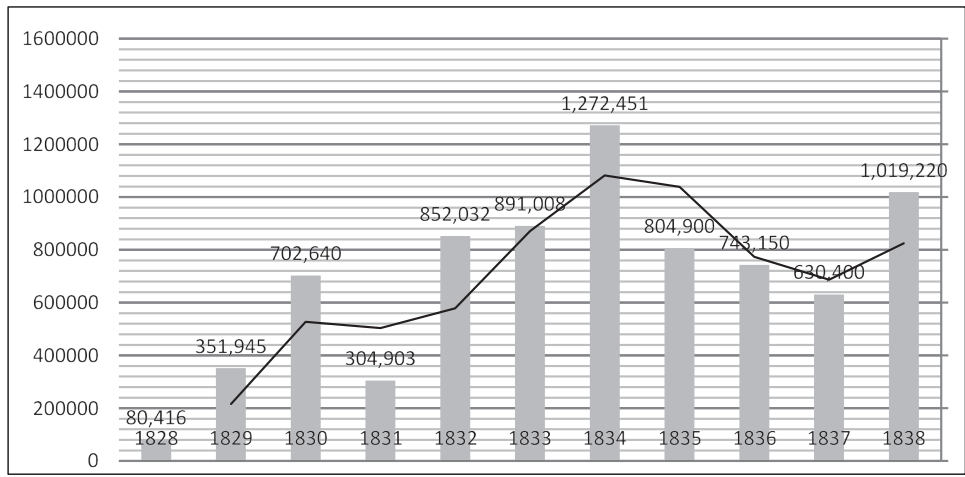

Fuente: Cajías, 1975, cuadros 12, 13, 15, 17, 19, 26 y 27.

puerto y el comienzo del movimiento relativamente importante de importaciones del puerto de Lamar.

10 ABNB, TNC 12123: Libro auxiliar de Potosi: "Razón de las partidas de efectos ingresados en esta Aduana con guía de la del Puerto de La Mar, con expresión de las fechas en que fueron libradas, su procedencia, nombre de los interesados, principales sobre los que se cobraron los derechos del 2\%, año de 1830". Comprende los años de 1827 a 1830. 
Según Fernando Cajías, el destino del 65\% de las importaciones de Lamar durante la primera década de funcionamiento del puerto tuvieron por destino a Potosí -donde se revendía a Chuquisaca, Tupiza y Tarija-, el resto iban especialmente a Cochabamba y Oruro, plazas que se abastecían tanto de Arica como de Cobija y provincias del norte de Argentina, principalmente Salta y Tucumán (1975, pp. 252-257). Estas ciudades actuaron como centros de redistribución hacia otras zonas de los Andes del sur.

En los primeros años de funcionamiento del Puerto, se advierte un continuo aumento en las importaciones, solo desacelerado durante los ańos de conflictos bélicos (1828, 1831 y 1835).

Del procesamiento de los libros de la aduana de Potosí de 1829, 1830 y $1831,{ }^{11}$ se desprende que, en promedio, $70 \%$ de las importaciones procedían de Cobija, mientras que el resto se repartía entre los circuitos Arica-Tacna-La Paz y Buenos Aires-Tucumán-Salta. Al mismo tiempo, se observa que las mercancías europeas salidas como reventas realizadas por las casas comerciales de Potosí tenían su origen en Lamar, con guías de los años 1829 y 1830. Los efectos ingresados a Potosí desde Cobija se revendieron en Oruro, Chuquisaca, Tarija, Porco, Chichas, Tupiza, Cochabamba, Tarata, Frontera, Laguna, Cinti, La Paz, Chayanta, Santa Cruz, Suruni y Laguna. ${ }^{12}$

11 ABNB, TNC 5119: Libro manual principal de la Aduana de Potosí, 1829; TNC 3119: Libro auxiliar y comprobantes de la Aduana de Potosí, 1829 y TNC 4779: Libro manual principal de la Aduana de Potosi, 1830.

12 ABNB, TNC 4779: Libro manual principal de la Aduana de Potosí, 1830; TNC 7408: Libro auxiliar principal de la Aduana de Potosí, 1830 y TNC 7449: Libro Auxiliar de Guias de la Aduana de Potosi, 1831. 
En las provincias del norte argentino, recién en 1829 comenzaron a ingresar a la aduana de Salta los efectos de ultramar comprados en Cobija. ${ }^{13}$ Las casas comerciales de Salta revendían estas mercancías a casas comerciales de Tucumán, Jujuy y Catamarca, con quienes mantenían fluidas vinculaciones. Hasta entonces, el $90 \%$ de las importaciones que arribaban a Salta, procedían de Buenos Aires y de comerciantes intermediarios de Tucumán, Córdoba y Santiago del Estero (Conti, 2003), lo que indicaría el comienzo de la competencia de dos circuitos de importaciones, los efectos ingresados desde el Atlántico y los ingresados desde el Pacífico, como se observa en el gráfico 2.

\section{Gráfico 2. Origen de las importaciones de efectos de ultramar ingresados a la aduana de Salta en 1829 y 1830}

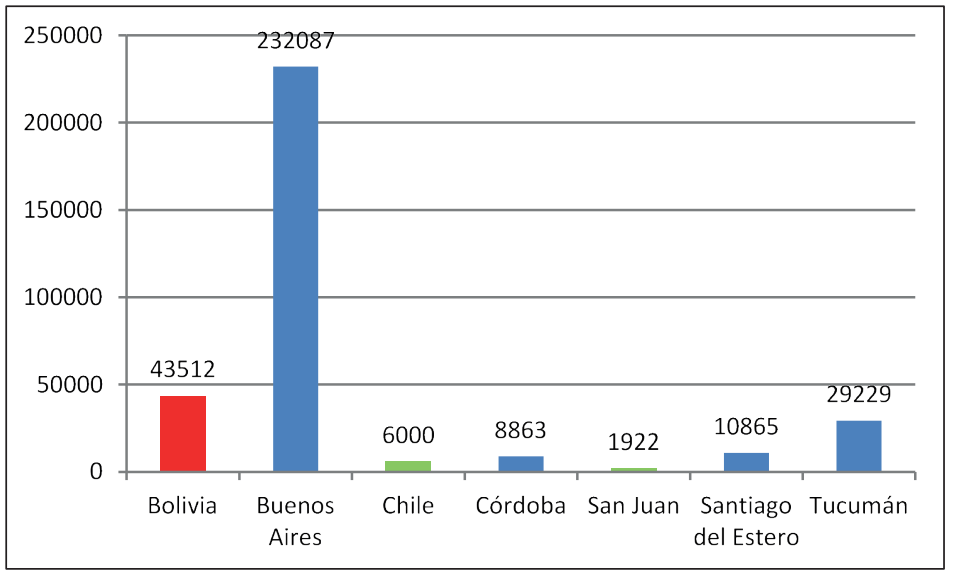

Fuente: AHS, LH 396 y 94. En el gráfico, corregir 'Tucunán’ por ‘Tucumán'.

13 Archivo Histórico de Salta (AHS), Libros de hacienda (LH) 396 y 94. 
Los siguientes años de la década de 1830 estuvieron signados por conflictos políticos en la región: las invasiones peruanas a Cobija (1831 y 1835), las consecuencias de la derrota unitaria en el norte argentino, derivada en emigraciones y pago de empréstitos y, finalmente, la guerra entre la Confederación Peruano-Boliviana y la Confederación Argentina (1837-1839), con enfrentamientos armados en la puna de Jujuy desde 1836, lo que provocó una marcada reducción en la circulación mercantil entre Salta y Cobija.

Entre 1831 y 1838, las casas comerciales de las provincias del norte argentino regresaron a sus giros de importaciones por el circuito atlántico. Por tanto, en esos años, las importaciones ingresadas a Cobija se dirigieron solo a las plazas comerciales bolivianas, especialmente a Potosí. ${ }^{14}$

Es interesante observar a través de las fuentes cómo, a partir de 1839, con el advenimiento de la paz en la zona, los circuitos de importaciones se volvieron a diversificar y aumentó paulatinamente el volumen y el valor de las mercancías ingresadas a la aduana de Salta procedentes del puerto de Lamar. $\mathrm{El}$ ingreso a la aduana de Salta de los efectos procedentes de Cobija se comenzaron a verificar a fines de 1839 y comienzos de 1840, por efecto de las distancias y las prácticas de los comerciantes de retirar sus efectos de la aduana; sin embargo, 252 en las guías y manifiestos está registrada la fecha de salida de

14 ABNB, TNC 2260: Libro copiador de guías de Potosí, 1833; TNC 5533: Libro copiador de guías expedidas, Potosí, 1834; TNC 2296: Libro auxiliar de guías de Potosí, 1835; TNC 10091: Libro auxiliar de alcabalas de Potosi, 1836; TNC 3731: Libro auxiliar de guías de la Aduana de Oruro, 1837. 
la mercancías de la aduana de Lamar, ${ }^{15}$ cuyos efectos de observan en el gráfico 3 .

Desde 1839, los comerciantes del sur peruano y del norte argentino volvieron a extender sus redes desde Cobija ( $\mathrm{La}-$ mar), cuyos resultados se observan en los libros de aduana de Salta en $1840,{ }^{16}$ año en el que se verifica el ingreso de mercancías con guías de Cobija del año 1839 por valor de $\$$ 18.620 y de 1840 por $\$ 7.500$ y de Arica por $\$ 360$. También se observa el pago de derechos de tránsito de mercancías que seguían hasta Tucumán (Conti, 2014), lo que evidencia la importancia que estaba tomando el puerto de Lamar para las provincias argentinas.

\section{Gráfico 3. Origen de las importaciones de efectos de ultramar en la aduana de Salta en $\mathbf{1 8 4 0}$}

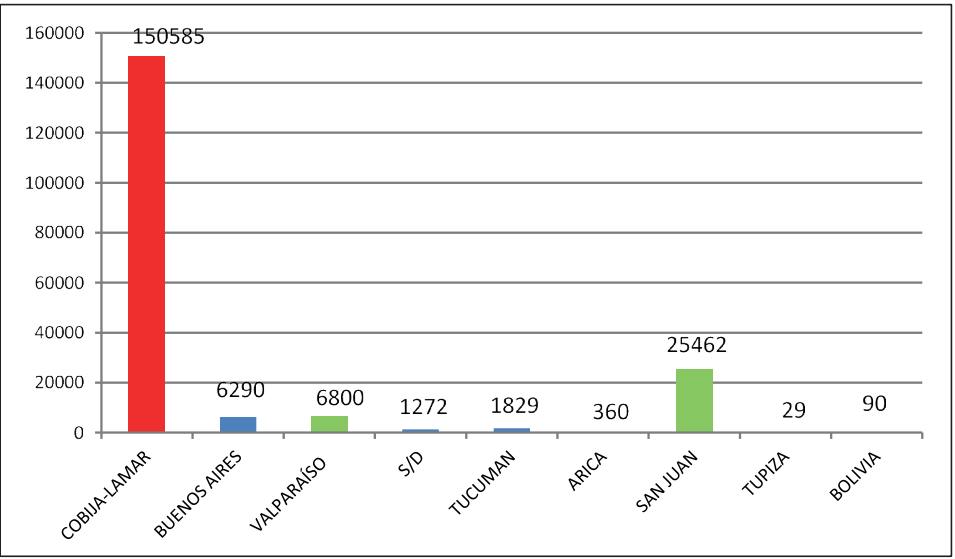

Fuente: AHS, LH 32.

15 AHS, LH 32.

16 Archivo Histórico de Salta (AHS), Libro de hacienda (LH) 32. 
El volumen de los flujos de mercancías en el circuito CobijaSalta siguió en aumento durante la década de 1840. En ello influyeron la supresión de los derechos de tránsito de todos los efectos ingresados al puerto de Lamar con destino a provincias argentinas, lo que contrastaba con los derechos de tránsito que se debía pagar en cada provincia de la Confederación Argentina y el estado de guerra en que se encontraban las provincias argentinas por las que transitaban las mercancías en el trayecto entre el puerto de Buenos Aires y su destino en el norte (Conti, 2014). Además, la Ley de Derechos Aduaneros de 1840 ratificaba que las mercancías que se internasen al puerto con destino a las provincias argentinas estaban libres de todo derecho, aun de tránsito, con la obligación de los mercaderes de comprobar su destino. ${ }^{17}$ Estos fueron alicientes suficientes para volcar el comercio de importaciones de las provincias limítrofes de Argentina definitivamente hacia Cobija.

\section{Movimiento de importaciones del puerto de Lamar en 1841}

El procesamiento y cruce de información de las aduanas de Lamar, Potosí y Salta en 1841 incluyó el monto en mercaderías sacada por cada comerciante, el nombre del mismo y de su representante en el puerto, el destino de la mercancía y los derechos abonados o adeudados, lo cual permite deducir el movimiento de importaciones del puerto y el destino de las importaciones extranjeras ingresadas. ${ }^{18}$

17 Ley de 13 de octubre de 1840, artículo 4, en Colección Oficial de Leyes, 1857, en ABNB.

18 ABNB, TNC 5531: Libro manual principal de la Aduana de Lamar del año 1841. TNC 9347: Libro de comprobantes de la Aduana de Lamar de 1841 y TNC 7342: Libro mayor de la Aduana de Lamar del año 
Los resultados obtenidos muestran que los efectos de ultramar salidos del puerto hacia el interior del continente estaban formados por una abrumadora mayoría de mercancías provenientes del mercado mundial y unas pocas producciones de otras regiones de América (bultos con añil, yerba mate, sombreros de paja y otros efectos americanos), que no son cuantitativamente relevantes.

Los destinos de estas mercancías fueron las ciudades de Potosí, Chuquisaca, Cochabamba, Oruro, La Paz, Salta (Argentina) y Tarapacá (Perú) en distintas proporciones, como se observa en el gráfico 5 .

- Las mercancías enviadas a plazas comerciales del interior de Bolivia suman un valor de $\$ 1.048 .493^{19}$ y las ciudades receptoras se encuentran, mayoritariamente -aunque no exclusivamente- en el sur, destacándose las de Potosí, Sucre (la capital de Bolivia) y Cochabamba.

- Mercancías enviadas a Tarapacá (Perú) por valor de \$ $9.678 .^{20}$

- Efectos enviados a Argentina (vía Salta) valuados en \$ $114.530 .^{21}$

1841. TNC.6730: Libro manual principal de la Aduana Nacional de Potosí, 1842. AHS, LH 32.

19 La Suma de los valores de las mercaderías retiradas de la aduana del puerto día por día según el Libro de comprobantes de la Aduana de Lamar de 1841, ABNB, TNC 9347.

20 La misma fuente que la anterior.

21 AHS, LH 32, Libro de Hacienda Pública de Salta para 1841 y ABNB, TNC 9347. 
La primera observación que surge del análisis de los destinos de las mercancías sacadas del puerto y sus valores es que el puerto de Lamar estaba abasteciendo a las plazas del sur de Bolivia. Otra observación se basa en la importancia mercantil de la ciudad de Potosí, como consumidora y reexportadora o redistribuidora a centros mercantiles; dicho en otras palabras, las casas comerciales de Potosí habían tomado relevancia en el sur boliviano y andino por los capitales que movilizaban, como lo observara Erick Langer (2003). Una tercera observación se relaciona con el aumento de la demanda de las provincias del norte de la Confederación Argentina; se hace la salvedad de que las mercaderías extraídas de la aduana con destino a las provincias argentinas estaban exentas de derechos, como se reproduce en el mismo libro de la aduana en cada salida de mercadería. ${ }^{22}$ Por tanto, las cifras valorativas fueron obtenidas del cruce de datos del libro de la aduana de Lamar con el libro de la aduana de Salta y se desagregaron los manifiestos de introducción de mercaderías provenientes de Lamar cruzando fechas, números de guías originales del puerto y comerciantes que retiraron o a quienes les fueran enviadas las mercancías.

Si se suman las mercancías valuadas y las no valuadas (con destino a provincias argentinas), se obtiene el universo de mercancías salidas por Lamar en 1841, cuyo valor asciende a $\$ 1.172 .701$. Al comparar esta cifra con las importaciones de 256 1838, año estudiado por Cajías, surgen nuevas ponderaciones que se representan en el gráfico 4 .

22 ABNB, Ley del 13 de octubre de 1840, en Colección oficial de leyes, decretos, órdenes y resoluciones supremas que se han expedido para el régimen de la República Boliviana. Impresa de orden del Gobierno Supremo con acotaciones y dos índices (t. sexto). Sucre, Imprenta de López, 1857 y TNC 9347. 


\section{Gráfico 4. Destino de las importaciones ingresadas por el puerto de Lamar en 1841}

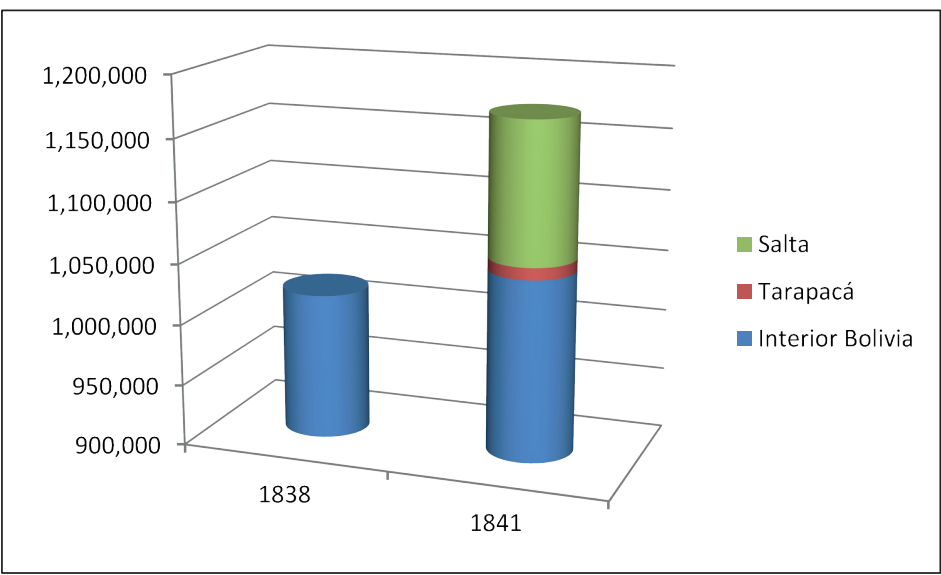

Fuentes: Cajías, cuadro 15, ABNB, TNC 9347 y AHS, LH 32.

Teniendo en cuenta que en el año 1838 (estudiado por Cajías) las mercancías solo se vendieron en el interior de Bolivia, debido al estado de guerra, el aumento de ventas en Lamar verifica una demanda de Salta y las provincias argentinas, que se fue incrementando en los ańos sucesivos por los aranceles comparativos con otros puertos (Buenos Aires y Valparaíso ${ }^{23}$ ), lo que contribuyó a un mayor movimiento de efectos por el puerto a lo largo de la década, así como a nuevas y múltiples redes que se extendían por las provincias argentinas.

Según se desprende de los libros aduaneros de Lamar, al computar los valores de las mercancías que salieron hacia ciudades de Bolivia (registradas como "al interior de la re-

23 Para el análisis de los aranceles de los puertos de Buenos Aires, Valparaíso y Lamar, véase Conti (2014). 
pública) y al desagregar por ciudades se aprecia mejor cuáles eran los centros de consumo y reventa de dichas mercancías: el $60.9 \%$ de las mercaderías (valuadas en \$ 639.412) tenía como destino las casas comerciales de la ciudad de Potosí; el $20.9 \%$ iba directamente a los comerciantes de Chuquisaca, lo que sumaba $\$ 220.171,{ }^{24}$ el $15.4 \%$ valuadas en $\$ 161.817$ fue a Cochabamba; el 1.8\% de mercaderías, con valor de $\$$ 19.606, fue a La Paz y el $0.7 \%$, formado por efectos valuados en $\$ 7.487$, fue a Oruro (véase el gráfico 5).

El gráfico 5 muestra, por un lado, la importancia de las casas comerciales de Potosí en el universo de las importaciones y, por otro lado, las vinculaciones del puerto de Lamar con las plazas del sur de Bolivia, ya que si bien los mercaderes de La Paz y Oruro participaban en los negocios de importaciones desde Lamar, dicha participación es ínfima, de lo que se deduce que el grueso del comercio de estas plazas se conectaba con Arica-Tacna y el sur del Perú. ${ }^{25}$

Al retomar la tercera observación relacionada con el aumento de la demanda de las provincias del norte de la Confederación Argentina, se realizó el ejercicio de agregar las mercancías destinadas al Perú y Argentina, con lo cual se abarcó el universo de lo introducido al mercado surandino desde el puerto de Lamar, lo que se muestra en el gráfico 5.

24 La ciudad de Sucre (Chuquisaca) también era surtida por las grandes casas de Potosí; aquí solo aparecen las mercancías que iban directamente desde el puerto de Lamar a Chuquisaca.

25 Véase el artículo de Cristina Mazzeo de Vivó en esta revista, que complementa los datos de las importaciones del interior del espacio surandino. 


\section{Gráfico 5. Destino de las mercaderías ingresadas por Lamar en 1841}

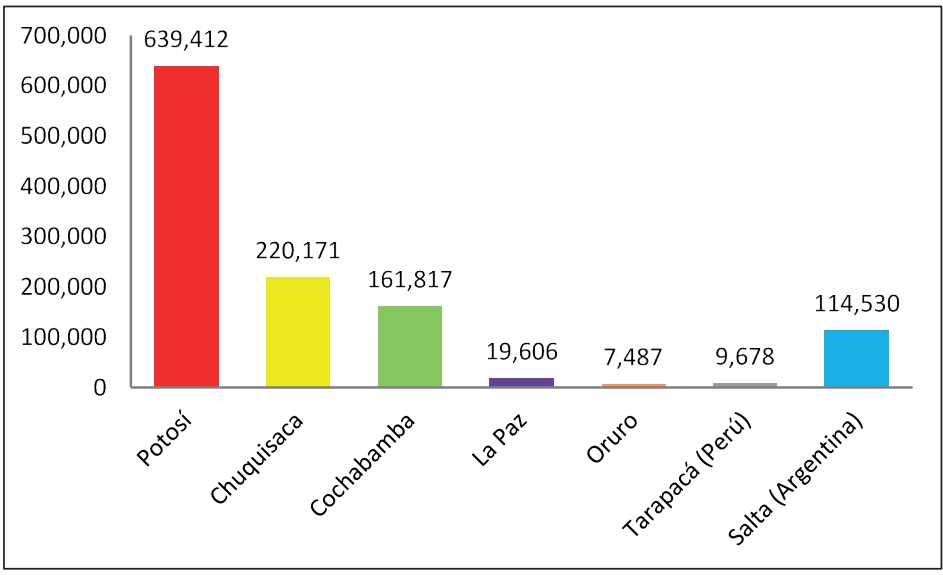

Fuentes: ABNB, TNC 9347 y AHS, LH 13.

En el gráfico 5 se ve la emergencia de la plaza de Salta como cuarto destino en importancia en el universo de las transacciones mercantiles realizadas desde el puerto de Lamar. Las casas comerciales de Salta eran, a su vez, redistribuidoras de mercancías hacia las provincias de Tucumán (Nicolini, 1992, anexo 2) Jujuy, Catamarca y Santiago del Estero (Conti, 2014, 2017).

El gráfico corresponde al año 1841, tomado como año testigo, sin embargo, a lo largo de la década de 1840 se fue incrementando la cantidad de comerciantes procedentes de Salta que compraban mercancías en el puerto de Lamar. ${ }^{26}$

26 ABNB, TNC 9360, 5547, 4572, 4573, 4574, 7964, 7804, 7805, 9348, 9606 y 7463. AHS, LH 95, 10, 8, 174 y 2. 


\section{Gráfico 6. Origen de las importaciones de efectos de ultramar ingresados a la aduana de Salta, 1840-1850}

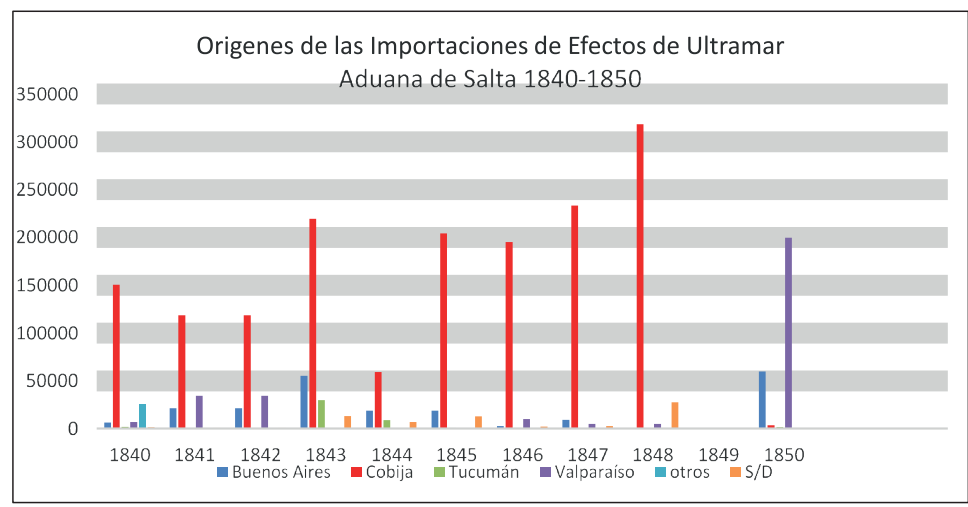

Fuente: AHS, LH 95, 10, 8, 174 y 2.

\section{Los comerciantes del puerto}

Durante la década de 1830, se había establecido en el puerto de Lamar un grupo de comerciantes y, desde allí, realizaban transacciones mercantiles con casas comerciales del interior del continente, amparados por la declaración de puerto franco de $1829 .{ }^{27}$ Algunos de esos primeros comerciantes eran aventureros que pusieron pulperías o almacenes con expendio de efectos importados; otros llegaron como representantes de las casas comerciales de Valparaíso y, ya entrada la década de 1830, Cajías observa las primeras casas comerciales importadoras del puerto de Lamar, a las que identifica con las firmas Hubert, Artola, Calsa, Lezica y José Frías, entre

27 Ratificada por la ley del 12 de octubre de 1832, que declaraba al puerto de Lamar "completamente franco y libre de todo derecho nacional, cualquiera sea su denominación". 
las que destacan las casas comerciales Tezanos Pinto y Cía., proveniente de Jujuy (Conti ${ }^{2013)}$ y la Casa Uriburu, Beeche y Cía., compañía comercial de salteños ${ }^{28}$ (Cajías, 1975, pp. 280-283). Estas casas comerciales, o sus representantes, se mantuvieron en el puerto en la década siguiente con distintas características, que se analizan a continuación.

En la década de 1840, se identifican dos grandes categorías de comerciantes que sacaban las mercaderías de la aduana de Lamar: los que vivían en el puerto y trabajaban como intermediarios para la venta a las casas comerciales surandinas y los dependientes de las casas comerciales del interior; a estas dos categorías de intermediarios, se suman los comerciantes que iban a comprar al puerto (tanto para sus propios negocios y casas o como intermediarios de otros). En general, las casas comerciales más importantes, tanto de Potosí como de otras plazas y mercados, tenían un dependiente en el puerto encargado de comprarles las mercancías y enviárselas. Las agrupaciones por categorías y las vinculaciones con las casas mercantiles del interior del espacio surandino fueron:

1) Los comerciantes que vivían en el puerto y retiraban las mercancías de la aduana de Lamar eran intermediarios que conformaban dos grupos diferenciados: a) Aquellos que solo trabajaban como comerciantes intermediarios entre la aduana de Lamar y las casas comerciales de otros puntos del interior surandino y b) Los intermediarios representantes, dependientes y apoderados de las casas comerciales del interior del continente, quienes vivían en

28 Tanto Dámaso de Uriburu como Gregorio Beeche ya residían en La Plata (Chuquisaca) desde la década anterior. 
el puerto de Lamar y su trabajo consistía en retirar las mercaderías para ellos o sus clientes.

2) Los comerciantes del interior surandino (Bolivia, Argentina y Perú) que se dirigían hasta Cobija ocasionalmente a fin de comprar mercancías en el puerto de Lamar para sus propias casas comerciales o reventa al mayoreo.

Seguidamente, se analizan estas categorías en función de los capitales que manejaban y su inserción en las redes mercantiles surandinas.

1.a) Una de las prácticas comerciales características de Cobija fue la utilización de comerciantes intermediarios entre el puerto y las casas comerciales del interior del continente. Su trabajo se basaba en la confianza y fidelidad que las compañías comerciales depositaban en él; era una actividad mercantil típica de los puertos, ya que todo mercader necesitaba una red segura, de la cual los comisionistas y los intermediarios constituían un eslabón indispensable (Braudel, 1984, pp. 121y ss.). Las compañías familiares solían colocar en el puerto al integrante más joven, como inicio de su carrera, práctica que se observa en Cobija en las casas comerciales Hubert y Cía. y Tezanos Pinto y Cía., que integraron a los hermanos menores temporalmente en el puerto al lado de un intermediario de confianza. Estas prácticas probablemente estuvieron relacionadas con el inhospitalario emplazamiento portuario y la lejanía de los centros urbanos.

En 1841, los comerciantes radicados en el puerto de Lamar que actuaban como intermediarios entre la aduana del puerto y los comerciantes del interior del espacio surandino eran José María Artola y Nicomedes García; ambos trabajaban solo la intermediación, es decir, no tenían tienda de venta directa al mayoreo ni al público. A fines de la década de 1840 apareció Luciano Durandeau. La firma Durandeau y Cía. compitió con Artola y Cía. y fueron los mayores in- 
termediarios entre el puerto y las casas comerciales del interior (Bolivia y norte argentino) durante la década de 1850 .

José María Artola. Comerciante de origen vasco, soltero, de 39 ańos de edad en $1841 .{ }^{29}$ Su trabajo consistía en la intermediación entre el puerto y sus clientes, que eran casas mercantiles y comerciantes de todo el interior surandino a través de la firma comercial Artola y Cía. Durante la década de 1840 figura en los libros de la aduana como el comerciante con mayor movimiento de capitales y manejaba los montos más altos en las transacciones con las casa comerciales del interior.

Al retirar los pedidos de sus clientes de la aduana, Artola firmaba pagarés a 3 y 5 meses; en las décadas de 1830 y 1840 , extraía personalmente las mercancías de la aduana, salvo durante el breve lapso de julio-agosto de 1841, cuando los bultos de la aduana fueron retirados, en su nombre, por Jorge de Tezanos Pinto $^{30}$ (dependiente-aprendiz). Según el Libro mayor de Lamar de $1841,{ }^{31}$ en su cuenta corriente había \$ 20.624 y 4 1/2 reales en concepto de alcabalas por efectos de ultramar del año.

29 José María Artola nació en San Sebastián (España) y según Cajías (1975, p. 82), radicó en Cobija en 1831. ANCH, Siglo XX, Volumen 54, Notarios de Valparaíso, 1840-1841, escribano Victorio Martínez, folios 152153. Datos obtenidos de la compra de la casa de Uriburu-Beeche en Cobija.

30 Jorge de Tezanos Pinto es el menor de los hijos de Manuel de Tezanos Pinto (véase Conti, 2013). En esos momentos aún trabajaba en la filial de La Paz de la casa Comercial Tezanos Pinto y Cía., junto a su primo y cuñado Pedro del Portal.

31 ABNB, TNC 7342, folio 83. 
De acuerdo con el Libro de la aduana de Lamar, ${ }^{32}$ en 1841 retiró mercaderías que envió a casas comerciales de las ciudades de Bolivia valuadas en $\$ 460.087$; esos valores representan el $43.9 \%$ del universo de internaciones de mercancías del puerto de Lamar en el interior de Bolivia. Este monto no incluye la mercadería enviada a las provincias de Argentina, ya que estaban exentas de derechos por la ley de $1840^{33}$ (para acceder a esos montos fue necesario cruzar los datos de extracción del puerto con los de introducción a Salta, Jujuy y Tucumán).

En 1841, sus clientes eran las casas comerciales más relevantes de Potosí, Chuquisaca, Cochabamba y Salta; también formaban parte de la red de Artola los mercaderes de Oruro y La Paz. En el siguiente cuadro se lista a los clientes de José María Artola en el año 1841.

32 ABNB, TNC, 9347.

33 Ley de 13 de octubre de 1840, artículo 4, en Colección Oficial de Leyes, 1857, en ABNB. 
Viviana E. Conti
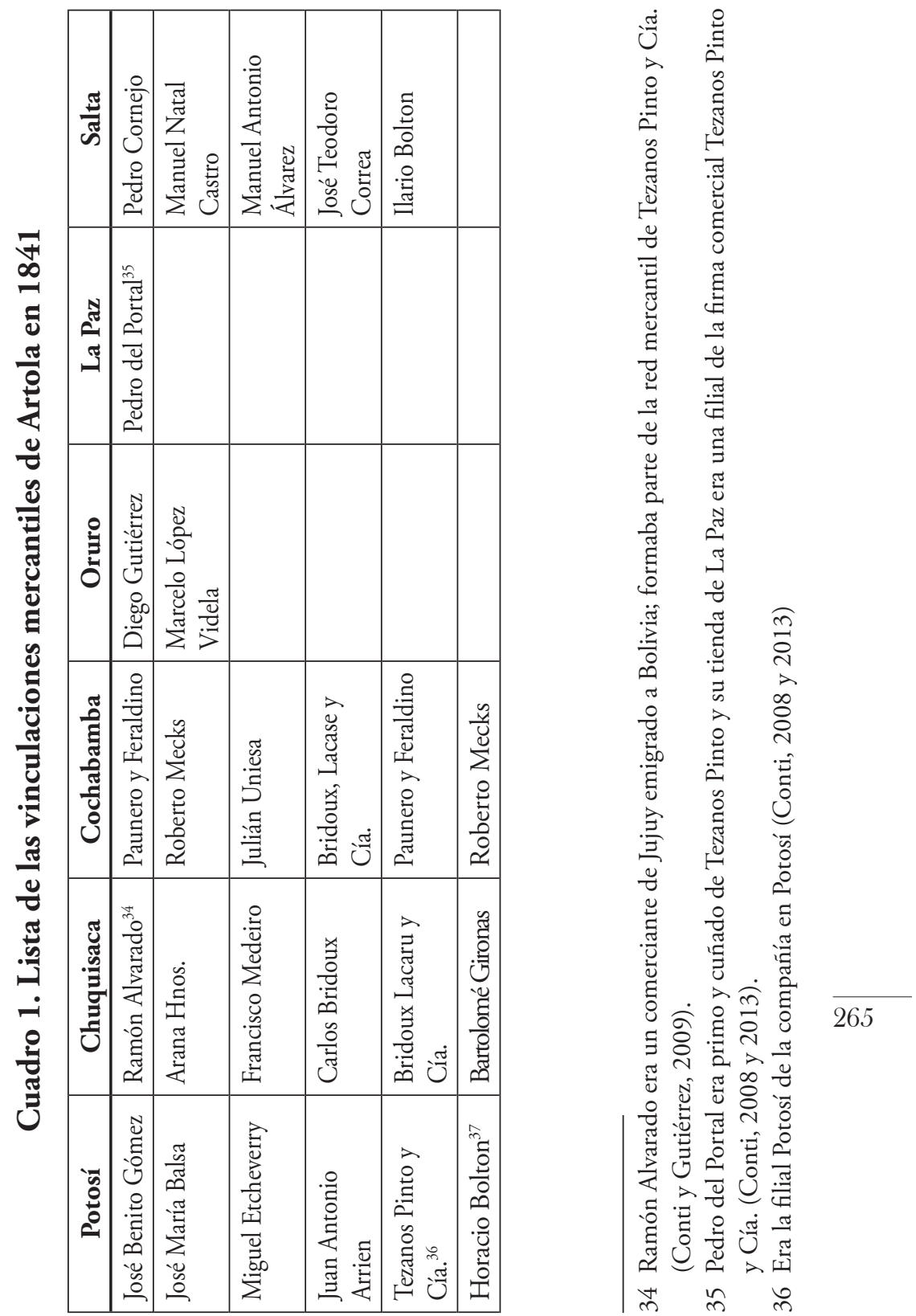

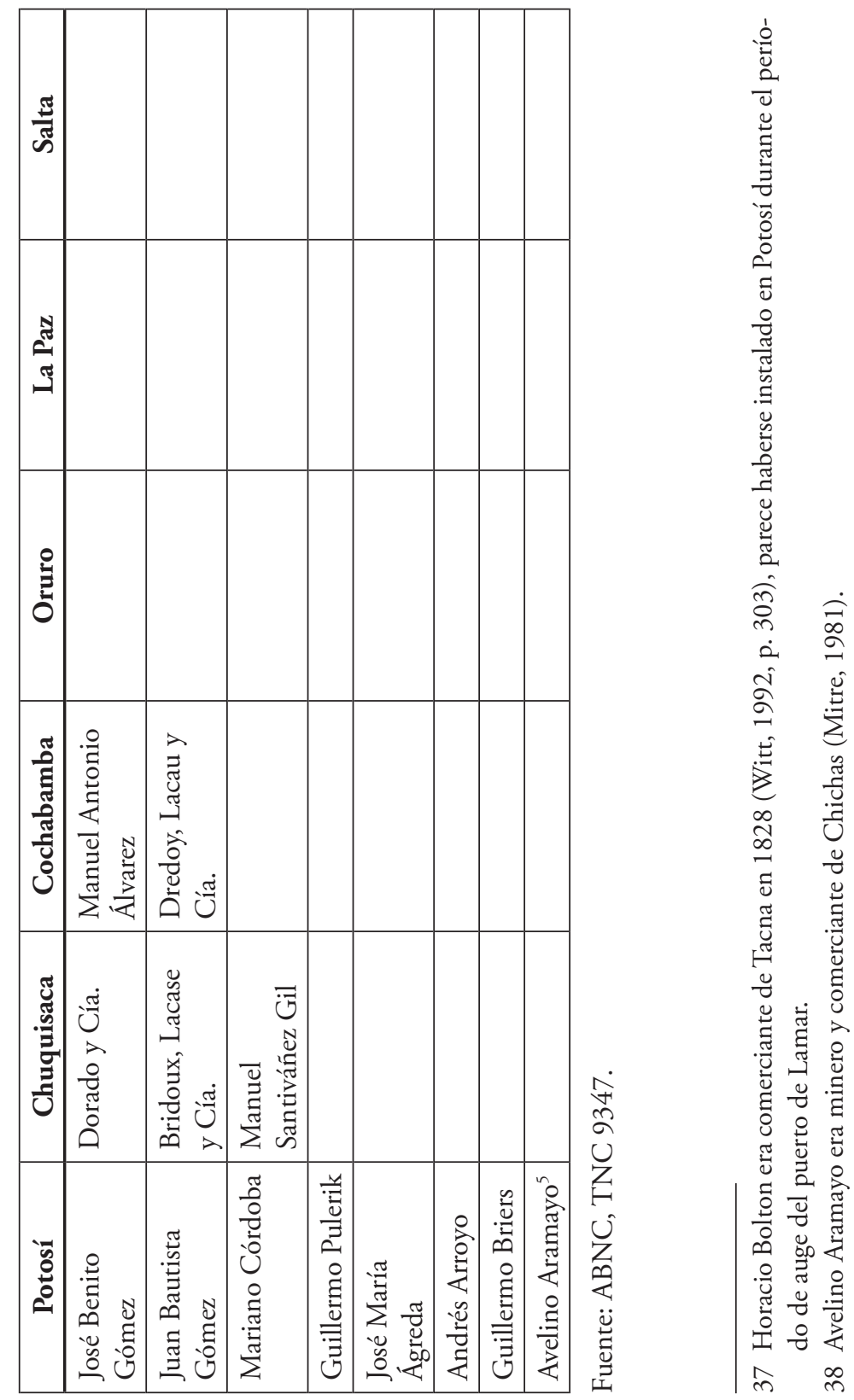
A continuación, se detallan los giros de importaciones realizados por José María Artola según los valores de las mercancías hacia cada destino. A la ciudad de Potosí, el valor de las mercancías giradas asciende a $\$ 147.947$; las casas comerciales que adquirieron mayores valores en mercancías importadas fueron Tezanos Pinto y Cía. y Horacio Bolton. A la ciudad de Sucre en Chuquisaca (capital de Bolivia), giró mercaderías importadas desde el puerto por valor de $\$ 193.897$ y las principales casas comerciales a las que envió mercancías fueron Dorado y Cía., Arana Hnos. y Bridux Lacase y Cía. A la ciudad de Cochabamba envió efectos valuados en $\$ 72.878$ y las casas comerciales con montos mayores de importaciones fueron las de Manuel Antonio Álvarez, ${ }^{39}$ Bridoux, Lacase y Cía. ${ }^{40}$ y Painero y Cía. A la ciudad de Oruro envió mercaderías ingresadas al puerto de Lamar por valor de \$ 5.990. En la ciudad de La Paz, su único vínculo era la filial de Tezanos Pinto y Cía., a quien mandó mercancías valuadas en $\$ 4.124$, a nombre de Pedro del Portal. Como puede observarse en el cuadro, importantes casas comerciales de Salta, importadoras y revendedoras, formaban parte de la red de Artola y se incrementaron en los años siguientes, a medida que el comercio de importación de Salta se fue volcando mayoritariamente a los negocios de importaciones a través del puerto boliviano.

El gráfico 7 muestra las vinculaciones de José María Artola expresadas en valores de las mercancías que sacó de la aduana del puerto de Lamar y envió al interior del continente.

39 Filial de su casa comercial de Salta.

40 Filial de la casa comercial de Chuquisaca. 


\section{Gráfico 7. Destino de las mercancías sacadas por Artola de la aduana de Lamar en 1841}

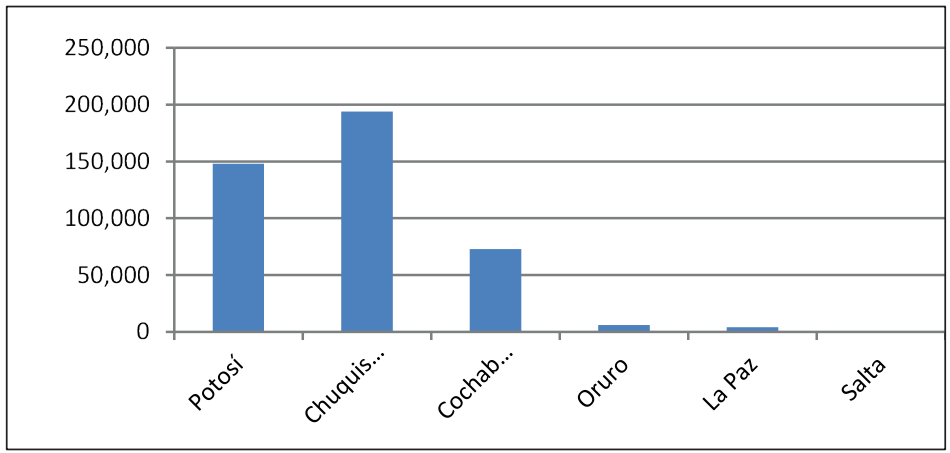

Fuente: ABNB, TNC 9347.

Nicomedes García. Retiraba personalmente los bultos de la aduana, donde dejaba pagarés a su nombre a 4 meses. No poseía tienda de venta al público, sino que actuaba de intermediario entre el puerto y las casas comerciales (de Bolivia y países limítrofes). Sus clientes estaban en las ciudades de Cochabamba, Potosí, Salta, Tucumán y Jujuy.

En 1841, García envió efectos importados desde el puerto de Lamar a la ciudad de Cochabamba, a la casa comercial Gumucio, Sancetenea y Cía. por un valor de \$ 39.201 y a Domingo Soruco (por \$ 150); en Potosí, su cliente era Mariano Córdoba, a quien remitió mercancías valuadas en \$ 7.133. En la ciudad de Salta, sus vínculos eran los comerciantes mayoristas Pedro Sáenz, Pedro Antonio Ceballos, Francisco Tejada y Guillermo Ormaechea; también formaban parte de sus vínculos mercantiles Juan Lebás, a quien le remitió a la ciudad de Tucumán mercancías por \$ 297 y a Jujuy. Suman- 
do solo las mercancías que iban al interior de Bolivia, Nicomedes García sacó del puerto de Lamar importaciones valuadas en $\$ 46.454$, que representan el $4 \%$ de las mercaderías salidas de la aduana con valores, ya que las que se remitían a las provincias de la Confederación Argentina estaban exentas de impuestos y, por lo tanto, se carece en este momento de sus montos. En el Libro mayor de Lamar, la cuenta de Nicomedes García figura con movimiento de capitales en derechos aduaneros por $\$ 4.138$ y 1 real. $^{41}$

1.b) En este grupo están los comerciantes que, teniendo casa comercial en algunas ciudades del interior surandino, contaban con su propio representante, dependiente o apoderado que actuaba como su intermediario en el puerto de Lamar y se encargaba de retirar las mercaderías para ellos o para sus clientes. En el cuadro 2 aparecen importantes casas comerciales de Potosí.

\section{Cuadro 2. Casas comerciales con representantes en el puerto de Lamar en 1841}

\begin{tabular}{|l|c|}
\hline Casas Comerciales & $\begin{array}{l}\text { Valor de las importacio- } \\
\text { nes retiradas del puerto en } \\
\mathbf{1 8 4 1}\end{array}$ \\
\hline Latorre, Lavayén y Cía. & $\$ 202.559$ \\
\hline Etcheverry y Cía. & $\$ 121.545$ \\
\hline Hubert y Cía. & $\$ 205.278$ \\
\hline
\end{tabular}

Fuente: ANB, TNC 9347. 
Hubert Ainé y Cía. Era la casa comercial formada por Pedro Hubert, francés, quien en 1841 contaba con 35 años y era soltero. Se había instalado en el puerto de Lamar en 1828 y figura en el censo de Cobija de ese ańo (Cajías, 1975: 81) como representante de Le Bris Berthaume ${ }^{42}$ y también hacía negocios de importaciones por su propia cuenta (Cajías, 1975: 282); durante las década de 1830 se fueron incorporando sus hermanos Augusto (en 1834), Juan (1836) y Luis (1841), oriundos de Pau y solteros.

En general, el arribo de un nuevo hermano significaba su ingreso a la casa comercial y su instrucción comprendía la permanencia por un tiempo en Cobija. En 1835, Pedro y Augusto, en sociedad, abrieron una filial de Hubert y Cía. en Chuquisaca, que pusieron a cargo de Enrique Beumont, agente de la casa de comercio de don Pedro Hubert y Cía.; la casa comercial y residencia familiar se encontraba e Potosi $^{43}$, mientras los hermanos se desplazaban entre Cobija y Chuquisaca. Formaban parte de una red de comerciantes franceses radicados en Bolivia, con quienes mantenían relaciones comerciales y sociales; designaron como factor a León Hormenet y luego a Juan Bautista Coret. Sus importaciones de efectos de ultramar procedían mayoritariamente de Francia y destacaban por los artículos de lujo y suntuosos (por ejemplo, arañas de cristal). Las transacciones comerciales en

42 Santiago Lebris era una comerciante francés asentado en Valparaíso, que había instalado una filial en Arequipa en 1821 con Juan Bautista Berthelaume (Condori, 2013, pp. 261-283).

43 Archivo y Centro Documental Bibliográfico Histórico Universidad Mayor Real Pontificia San Francisco Xavier de Chuquisaca (AHUSFX), Notaría Dra. Marina Sánchez. Escribano Celestino Valda 1-4-1 a, fs. 134$135 \mathrm{v}$. 
Valparaíso las realizaban a través de Uriburu Beeche y Cía. y Naylors Boardman y Cía. ${ }^{44}$

En 1841, los hermanos instalados en las plazas interiores de Bolivia pusieron como representante en el puerto a Domingo Latrille, quien se encargaba de retirar las mercaderías de la aduana, donde dejaba pagarés a 3 y 5 meses a nombre de $\mathrm{Hu}$ bert y enviaba las mercancías a la casa comercial en Potosí y, eventualmente, a clientes de Hubert en Potosí y Chuquisaca. En ese año se había incorporado Luis Hubert, en calidad de aprendiz, en Cobija. ${ }^{45}$ Ambos actuaban como intermediarios entre la aduana de Lamar y la casa Hubert o sus clientes.

Durante el año 1841, la Casa Hubert y Cía. sacó de la aduana de Lamar mercaderías valuadas en \$205.278, que representan el 20\% de las mercaderías salidas de la aduana. El 74\% de esa cantidad estaba formada por importaciones que fueron a su casa comercial en Potosí y Chuquisaca (\$150.677). El $26 \%$ restante lo enviaron directamente desde el puerto a sus clientes: a Evaristo Etchecopar \$ 697; a José Santos García \$ 3.980; a Adrian Groc en Chuquisaca \$ 16.139; a P. N. Costas en Potosí \$ 13.134; a Avelino Aramayo en Potosí \$ 20.651 y un envío a Salta (sin monto, destinatario ni cantidad). En el Libro mayor de Lamar, Hubert y Cía. figura con movimiento de capitales en derechos aduaneros por \$9.294 y 6 reales en $1841 .{ }^{46}$

44 AHP, PN 211, fs. 530-531v. Escribano José Félix Hernández. Potosí, 17 de diciembre de 1835 .

45 ABNB, TNC 9347.

46 ABNB, TNC 7342, f. 82. 
Latorre, Lavayen y Cía. Tenía casa comercial en Potosíi ${ }^{47}$ y filial en Cochabamba. El representante de la casa en el puerto era Diego Lam, quien como intermediario retiraba la mercancía de la Aduana y firmaba pagarés a 3 y 5 meses a nombre de la casa comercial; también se encargaba de mandar los bultos a la casa de Potosí, a la filial y a sus clientes (comerciantes en Bolivia). ${ }^{48}$ Durante 1841 , retiró de la aduana de Lamar mercaderías por valor de \$202.559, de las cuales el $91.6 \%$ ( $\$ 185.618)$ fue destinada a sus casas comerciales en Potosí y Cochabamba; el resto fue enviado a Agustín Pío Ramos en Oruro (\$1.498); a José María Ágreda en La Paz (\$ 349); a Mateo Belmonte en La Paz (\$14.991) y a Alejandra Ameller de Frías en Chuquisaca (\$103)..$^{49}$ En el Libro mayor de Lamar, Latorre, Lavayén y Cía. figura con movimiento de capitales en derechos aduaneros por $\$ 10.553$ y 6 reales. ${ }^{50}$

Etcheverry y Cía. La casa comercial estaba en Potosí. En 1841, compró en la aduana de Lamar mercaderías por \$ $121.545^{51}$; el $71 \%$ de ellas (valuadas en $\$ 86.332$ ) fue para su casa comercial en Potosí; envió a sus clientes José Montero de Potosí mercaderías por valor de $\$ 24.183$ y a Domingo Larady, también de Potosí, por \$11.030. Figuran dos envíos de mercadería a Salta, pero sin el nombre del destinatario ni monto (libres de impuestos). En el Libro mayor de Lamar,

47 AHP, EN 278, Escribano Jaime Calvimonte, folio 5. Formación de la sociedad mercantil Latorre, Lavayen y Cía.

48 ABNB, TNC 9347.

49 Además, figura un retiro de mercadería por parte de José María Whiting, que envió a Modesto Lavayen en Potosí, por \$ 377 y 1 real. ABNB, TNC 9347, f. $52 \mathrm{v}$.

50 ABNB, TNC TNC 7342, f. 81.

51 ABNB, TNC 9347. 
Etcheverry y Cía. figura con un movimiento de capitales en derechos aduaneros por $\$ 5.252$ y 7 reales. ${ }^{52}$

Como se observa en el gráfico 8, cinco comerciantes mayoristas, Artola, García, Hubert, Latorre y Etcheverry sacaron y afianzaron en la aduana de Lamar el 99\% de las mercaderías salidas del puerto, que revendían a comerciantes del espacio surandino.

\section{Gráfico 8. Comerciantes que retiraban mercancías de la aduana de Cobija en 1841 (en valores de las mercancías)}

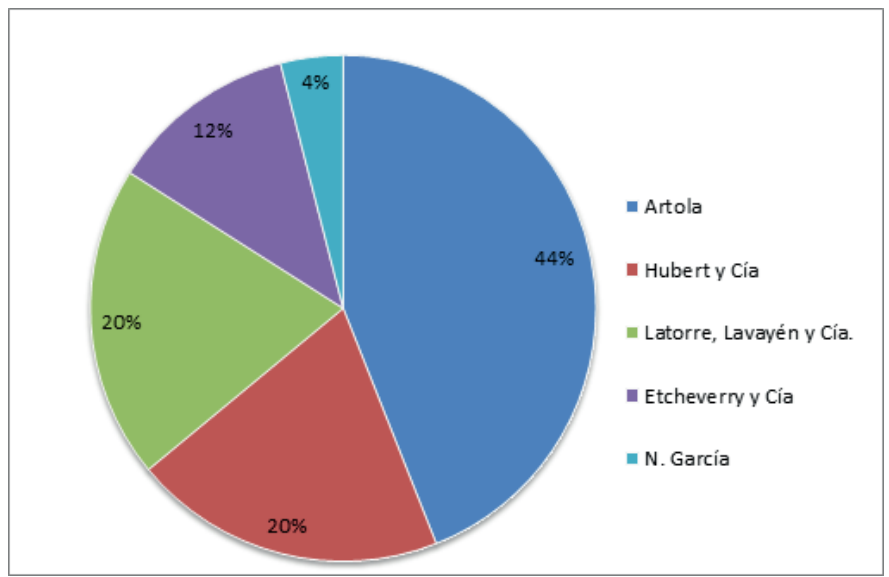

Fuente: ABNB, TNC 9347.

2) Los comerciantes del interior surandino (Bolivia, Argentina y Perú) que se trasladaban hasta Cobija para comprar mercancías ingresadas en el puerto de Lamar, destinadas 
a sus propias casas comerciales o para su reventa al mayoreo, en 1841 representaban 1\% de las compras en la aduana y son los que se listan a continuación.

José Teodoro Correa. Comerciante de Salta, retiró personalmente los bultos en la aduana y los reenvió a su tienda y a sus clientes de Salta. No pagó derechos, pues estaba sujeto al artículo $4^{\circ}$ de la ley del 13 de octubre de 1840, según el cual solo estaba obligado a presentar la manifestación de que los bienes fueron introducidos en la República Argentina. Las mercancías compradas en el puerto eran 223 bultos que remitió a su propia casa (a nombre de Juan A. Correa) y como intermediario de Manuel Natal Castro en Salta. A partir de entonces, José Teodoro Correa figura como cliente y destinatario de Artola. Manuel Natal Castro, por su parte, realizó compras de mercancías de ultramar en Valparaíso y las despachó a Lamar en el bergantín Packet consignados a Nicomedes García, quien se las remitió a Salta.

Juan Fagalde. Comerciante de Potosí que compró en el puerto para su propia casa comercial; realizó una sola compra de $\$ 24$.

José María Ágreda. Compró para su casa en Potosí mercadería por \$11.649 y 3 reales. Retiró él mismo de la aduana y puso pagarés a 3 y 5 meses. Fue la única oportunidad en que fue al puerto, ya que era cliente de Latorre, Lavayén y Cía. y de Artola. No figura en las cuentas corrientes del Libro mayor.

Salvador Bermúdez. Compró para llevar al Perú (a Tirana: $\$ 5.226$ y 6 reales, a Pica: $\$ 2.161$ y 2 1/2 reales y a Carmina: $\$$ 2.289 y 5 reales, todos pueblos de Tarapacá). Retiró él mismo 
de la aduana y dejó pagarés a 3 y 5 meses por los derechos de tránsito correspondientes. La suma de las mercancías adquiridas en Lamar asciende a \$ 9.677 y 5 reales. No figura en el Libro mayor en cuentas corrientes.

En los años siguientes, al ritmo del crecimiento del puerto y el aumento de las demandas, este sector fue creciendo en número y en porcentaje de adquisiciones de mercancías en la aduana de Lamar.

\section{Conclusiones}

Se ha analizado el movimiento comercial del puerto de Lamar (Cobija) en profundidad durante el año 1841. Se cuantificaron las importaciones que salieron de la aduana, los destinos a los que fueron enviadas y los comerciantes intervinientes, tanto en la extracción de las mercancías como en el destino final de las mismas.

Se advierte que el territorio surandino se encauzó decididamente hacia los puertos del Pacífico y abandonaron coyunturalmente el puerto atlántico. Los nuevos puertos de la era republicana fueron abasteciendo a los territorios del interior y zonas cercanas que se beneficiaron por las distancias y los fletes, lo que ya había sido observado por Joseph Pentland en 1826 , antes de entrar en funcionamiento el puerto de Lamar.

En este esquema, el puerto boliviano canalizó al comercio cercano y desplazó al puerto de Buenos Aires, convirtiéndose en el polo de un subcircuito que comprendía el sur de Bolivia, con centro en Potosí y Chuquisaca y se extendió al norte de la Confederación Argentina con centro en Salta. 
El espacio norte de Bolivia siguió comunicado con el corredor Arica-Tacna, a pesar de que el puerto políticamente más beneficiado (en aranceles) era el de Lamar; las distancias, fletes y las redes mercantiles preexistentes fueron determinantes en la elección del puerto para la provisión de las importaciones $^{53}$. Ambos puertos (Lamar y Arica) se complementaron con Valparaíso, que se fue convirtiendo en el mayor puerto del Pacífico sur, donde se asentaban las sucursales de las casas comerciales europeas y norteamericanas

El puerto de Lamar benefició a su zona de influencia y, principalmente, a las casas comerciales importadoras establecidas en Potosí y Salta. Se observa que las casas comerciales de Potosí habían tomado relevancia en el sur boliviano y andino por los capitales que movilizaban, lo que ocurriría en los años siguientes con las casas mercantiles de Salta. Ambas plazas se vieron beneficiadas con un crecimiento comercial a la sombra del puerto de Lamar.

Se identificaron y agruparon a los comerciantes del puerto por categorías y prácticas mercantiles, lo que permitió observar las redes comerciales que establecieron en el interior del espacio surandino. Sin embargo, los lazos comerciales también tenían peso a la hora de elegir un puerto, como se nota en algunos comerciantes de La Paz, Oruro y Tarapacá, que 276 adquirían los efectos del mercado mundial a intermediarios de Lamar. Estos lazos se extendían a los comerciantes minoristas y consumidores de distintas plazas, tema que no se aborda en este trabajo.

53 Los artículos de Mazzeo de Vivó y de Rosenblitt en este mismo número de la revista complementan esta conclusión. 
Recibido: 07 de junio de 2017

Aprobado: 20 de abril de 2018

\section{Fuentes}

Archivo y Biblioteca Nacionales de Bolivia

- Tribunal Nacional de Cuentas

- Biblioteca René Gabriel Moreno

- Colección Oficial de Leyes

Archivo y Centro Documental Bibliográfico Histórico, Universidad Mayor Real Pontificia San Francisco Xavier de Chuquisaca

- Notarios de Sucre

Archivo Histórico de Potosí

- Escrituras Notariales

- Prefectura Departamental

- Hemeroteca

Archivo Histórico de Salta

- Libros de hacienda pública

Archivo Nacional de Chile, archivo siglo XX

- Notarios de Valparaíso 


\section{Bibliografía}

Albeck, M. E., Conti, V. y Ruiz, M.

(2003) Entre les oasis d'Atacama et la Puna de Jujuy: voies de communication et mobilité dans la longue durée. Histoire des Alpes, 8: 79-98.

Anonimo

(1863) Camino carretero de Cobija a Calama. En: Litoral boliviano. Proyecto para la construcción de un camino carretero entre Cobija y Alto de Tames en la dirección de Calama y Caracoles. Valparaíso: Imprenta del Mercurio. Biblioteca Gabriel René Moreno, ABNB.

Assadourian, C. S.

(1983) El sistema de la economía colonial. El mercado interior, regiones y espacio económico. México: Nueva Imagen.

Braudel, F.

(1984) Civilización material, economía y capitalismo. Siglos XV-XVIII (tomo 2: Los juegos del intercambio). Madrid: Alianza.

Cajías, F.

(1975) La provincia de Atacama (1825-1842). La Paz: Instituto Boliviano de Cultura.

Condori, V.

El francés Santiago Le Bris y la primera casa comercial de Arequipa 1821-1850. Bulletin de I'Institut francais d'Etudes Andines 42 (2). https://doi.org/10.4000/bifea.4069

Conti, V.

(2001) Salta entre el Atlántico y el Pacífico. Vinculaciones mercantiles y producciones durante el siglo XIX. En S. Bandieri (Coord.), Cruzando la Cordillera... la frontera argentino-chilena como espacio social (pp. 
233-261). Neuquén: Universidad Nacional del Comahue

Conti, V.

(2003) Circuitos mercantiles, medios de pago y estrategias. Salta y Jujuy entre 1820 y 1852 . En M. A. Irigorin y R. Schmit (Eds.), La desintegración de la economía colonial. Comercio y moneda en el interior del espacio colonial (1800-1860). Buenos Aires: Biblos.

Conti, V.

(2007) Vinculaciones mercantiles entre el norte Argentino y los puertos del Pacífico a través de las importaciones (1825-1852). En M. Guerra Martinière, C. A. Mazzeo de Vivó y D. Rouillon Almeida (Eds.), Historias compartidas: Economía, sociedad y poder, siglos XVI-XX (pp. 371-420). Lima: Pontificia Universidad Católica del Perú.

Conti, V. (2008)

Circulación de mercancías y mercaderes por el espacio surandino (1820-1850). En T. Pereira y A. Ibáñez (Eds.), La circulación en el mundo andino, 17601860 (pp. 219-252). Santiago de Chile: Fundación Mario Góngora, Alfabeta Impresores.

Conti, V. (2013)

Comercio y comerciantes en el espacio surandino, de la colonia a la república. Tezanos Pinto y Cía. En Anuario de Estudios Bolivianos, Archivisticos y bibliográficos, 19.

Conti, V.

(2014) El puerto de Lamar en el Pacífico sur. Vinculaciones con el interior del espacio surandino. Flujos y redes mercantiles, 1827-1850. En Anuario de Estudios Bolivianos, Archivisticos y Bibliográficos, 19: 395-426. 
Conti, V.

(2017) Circuitos comerciales y redes mercantiles del interior surandino, desde el puerto boliviano de Cobija (1827-1845). En G. del Valle Pavón y A. Ibarra, Redes comerciales y mercados americanos en la economía global, siglos XVII-XIX. México: Instituto de Investigaciones Dr. José María Luis Mora.

Conti, V. y Gutiérrez, M.

(2009) Empresarios de los Andes, de la colonia a la independencia. Dos estudios de casos de Jujuy. América Latina en la Historia Económica, segunda época (32).

Dalence, J. M.

(1975) Bosquejo estadistico de Bolivia. La Paz: Universidad Mayor de San Andrés.

Escobari de Querejazu, L.

(2014) Producción y comercio en la historia de Bolivia colonial, siglos XVI-XVIII. La Paz: IEB-Plural.

Langer, E. D.

Bajo la sombra del cerro rico. Redes comerciales y fracaso del nacionalismo económico en el Potosí del siglo XIX. Revista Andina 37: 77-94.

Mata, S.

(1993) Los comerciantes de Salta a fines del siglo XVIII. Anuario 16. Rosario: Instituto de Investigaciones Históricas de Rosario.

Mazzeo de Vivó, C. A.

(2013). La interconexión de los puertos del Pacífico en los primeros ańos independientes. En Primer Congreso Peruano de Historia Económica, Ayacucho.

Mazzeo de Vivó, C. A.

(2016) Conflictividad politica unidad económica, Arica y su importancia, durante la Confederación Peruano Boli- 
viana 1836-1839. Trujillo, Asociación Peruana de Historia.

Milletich, V.

(2000) El Río de La Plata en la economía colonial. En E. Tándeter (Dir.), La sociedad colonial. Buenos Aires: Sudamericana. Historia Argentina, t. II.

Mitre, A.

(1981) Los patriarcas de la plata. Estructura socioeconómica de la minería boliviana en el siglo XIX. Lima: Instituto de Estudios Peruanos.

Nicolini, E.

(1992) Circuitos comerciales en Tucumán entre 1825 y 1852. DATA Revista de Estudios Andinos y Amazónicos, INDEAA (2): 63-95.

Palliere, L.

(s. f.) Diario de viaje por la América del Sud [el viaje es de 1858]. Buenos Aires: Ediciones Peuser.

Pentland, J. B.

(1975). Informe sobre Bolivia 1826. Potosí: Impresión Casa de la Moneda.

Philippi, R.

(1860) Viaje al desierto de Atacama, hecho de orden del Gobierno de Chile en el verano 1853-54. Halle en Sajonia, Librería de Eduardo Anton.

Reglamento y aranceles reales para el comercio libre de España a Indias de 12 de octubre de 1778. Madrid: Imprenta de Pedro Marín.

Roca, J. L.

(2011) Ni con Lima ni con Buenos Aires, la formación de un estado nacional en Charcas, Bolivia. La Paz: Plural Editores, IFEA. https://doi.org/10.4000/books. ifea.7186 
Rosenblitt, J.

(2014). De arrieros a mercaderes. Orígenes de los comerciantes de la región Tacna-Arica, 1776-1794. Revista de Indias, LXXIV (260). https://doi.org/10.3989/revindias.2014.002

Rosenblitt, J.

(2017). Cuatro monopolistas extranjeros establecidos en Tacna. Prospección a los mercaderes británicos en la región Tacna-Arica, 1830-1860. América Latina en la Historia Económica, 24 (3): 41-70.

Sánchez Albornoz, N.

(1965). La saca de mulas de Salta al Perú. 1778-1808. Anuario VIII. Rosario: Instituto de Investigaciones Históricas de Rosario.

Sanhueza, C.

(2011). Atacama y Lípez. Breve historia de una ruta: escenarios históricos, estrategias indígenas y ritualidad andina. En L. Núñez y A. Nielsen (Eds.), En ruta. Arqueología, historia y etnografía del tráfico surandino. Córdoba: Grupo Encuentro Editor.

Toledo, E.

(1963). El comercio de mulas en Salta: 1657-1698. Anuario VI. Rosario: Instituto de Investigaciones Históricas de Rosario

Tschudi, J. J. von

282 (1860). Viaje por las Cordilleras de los Andes de Sudamérica, de Córdoba a Cobija en el Año 1858. Buenos Aires, Boletín de la Academia Nacional de Ciencias.

Witt, H.

(1992). Un testimonio personal sobre el Perú del siglo XIX (v. I: 1824-1842). Lima: Banco Mercantil. 